\title{
Impact of Price Reduction Sensitivity on Brand Switching and Storage: The Case of Saudi Arabia
}

\author{
Imen Zrelli ${ }^{1} \&$ Mbarek Rahmoun ${ }^{2,3}$ \\ ${ }^{1}$ Department of Human resources, College of Business, University of Jeddah, Khulais, Saudi Arabia \\ 2 Department of Business Administration, Faculty of Applied Studies, King Abdulaziz University, Jeddah, Saudi \\ Arabia \\ ${ }^{3}$ University of Carthage, Tunisia \\ Correspondence: Mbarek Rahmoun, University of Carthage, Tunisia. E-mail: mbarekrahmoun@yahoo.fr
}

Received: June 23, 2020

Accepted: July 30, 2020

Online Published: August 14, 2020

doi:10.5430/rwe.v11n4p23

URL: https://doi.org/10.5430/rwe.v11n4p23

\begin{abstract}
Sensitivity to price promotions has recently caught the attention of marketing researchers and professionals. It is true that lowering prices makes it possible to attract customers who are sensitive to such reductions, but is it profitable for the company to target those who are most sensitive to price reductions? The assumption is that sensitivity to price reductions reinforces brand switching and decreases re-purchasing rates. In order to test the relationships between the different variables, a two-section questionnaire was designed. The first section probes for information on the brands usually acquired and the second section targets re-purchasing behavior after buying at a price reduction. Thus, 231 Saudi female consumers were selected as a sample representing voluntary purchasers of hand washing powder. The results of this study highlight the impact of price reduction sensitivity on post-purchase behavior.
\end{abstract}

Keywords: price reduction sensitivity, brand switching, storage, re-purchasing

The impact of price reduction promotions is observable during economic crises, an example would be during the 1970s unfavorable economic conditions due to the first oil shock. During the 1980s, economic conditions fairly improved. Customers grew wary of the scope and quality of products than to their prices. At the end of the decade and at the beginning of the 1990s, economic conditions worsened again as consumption and other macroeconomic indicators progressively decreased. Customers showed preference to cheaper alternatives rather than partially upholding consumption. Several studies conducted in the early 1990s on consumer behavior showed that a large proportion of the individuals surveyed had changed their habits. Some said they were more careful about prices, others preferred quality, and a minority said they were looking primarily for service quality. These findings favored the development of price-based retailing. Price reduction initiatives allow companies to develop their customer portfolios and attract new customers (Froloff, 1992). Sometimes, price reductions would only be possible by lowering the intrinsic quality of the product to a certain extent. Buyers paying a low price will acquire a product or service that has somewhat a low quality than the usual item.

For many researchers, buying during price reduction campaigns encourages customers to switch brands (Dodson, Tybout and Sternthal, 1978). Brand switching behavior is presented as a negative outcome of the sensitivity to price reductions that affects consumer post-purchase behavior.

Similarly, several authors presented storage behavior as a factor that affects the subsequent purchase of the same brand. The lower the cost of storage, the more negatively it affects consumption and inter-purchase interval (Chandon and Wansink 2002).

\section{Price Reductions}

While production nowadays is not a problem, marketing is: sales conditions have become more complex, competition has become fiercer, the customer is much more demanding, and sales are no longer automatic. A price reduction initiative is a highly recommended alternative to solve this. The importance of price reductions for companies is seen in two facts: on the one hand, more than half of the total volume of frequently purchased products is sold at a price reduction, and on the other hand, expenditure on products sold at a price reduction event compared to other periods is significant. Pricing decision is the most important decision made by food manufacturers (Rezgar 
and Mohammed, 2019; Steven et al., 2020).

Chandon (1994) surveys research on price reduction and lists "more than 200 articles published between 1984 and 1994 against only 38 articles between 1965 and 1983". Some authors, like Froloff (1992), have studied the issue in terms of factors, distinguishing between external (speed, customer saturation in the face of excessive advertising, trivialization of products and brands, etc.) and internal factors (preference for short-term results).

To examine price reductions, one should first of all focus on the different types of price reduction techniques. The most frequent method is the special offer. With this technique, a firm grants a special and a temporary discount to customers. Another price reduction method is discount vouchers. In this case, the firm issues a certain number of discount vouchers to be used to purchase particulars goods. The three-for-two, or five-for-four method is the least used method and is only used for chocolate, soaps or other such items. The refund offer is generally used during the launch of the product allowing customers to try the product. This method justifies deferred discounts on the price of a given product and on the presentation of proof of purchase (Zollinger and Desmet, 1997, Gao, Zhang and Mittal, 2017).

By temporarily reducing its prices to a minimum that covers its expenses, a firm hopes to temporarily increase the use of its products, hence its market share, and retain a portion of this gain when prices bounce up to normal (Sudipt and al., 2014).

Such a price reduction move can help to strengthen product positioning and advertising. It allows for a flexible adjustment of prices to competitive levels. It is necessary to adapt to changes in demand. This approach forces firms to constantly improve their skills in order to stay in the race. This state of competition results in constant aggressiveness, because a product can barely be designed when it is already technically out of dat. Therefore, it is necessary to make its sales tool more effective. Price reductions therefore seem to be an effort to stimulate demand.

However, while price reductions optimize sales, the quest for short-term profit calls into question its effectiveness and can even negatively affect post-purchase behavior. Faced with this challenge, price-sensitive customers buy more of a single brand in order to stock at home. They may also be deterred from buying and may switch to an even more expensive offer (Colombier and Hourcade, 1989).

\section{Sensitivity to Price Reductions and Brand Switching}

\subsection{Negative Effects of Price Reductions}

It is well known that price reduction offers can be paradoxical and be both the worst and the best of things. In the short term they are profitable, while in the long term they do not always guarantee customer loyalty. Such shortcomings in no way diminish the interest in price reduction, which remains a central theme that justifies the interest of many researchers in trying to identify customers who are sensitive to the effects of these reductions.

Several authors have presented brand switching as a negative effect of sensitivity to price reductions. For example, Gupta (1988) found that more than $84 \%$ of an increase in sales during a price reduction initiative resulted from brand switching. Because price reductions attract, in the first place, customers who are sensitive to these reductions, it can be concluded that a customer who is sensitive to price reductions is a brand switcher. According to Chandon (1994), a price-sensitive customer buys many different brands, which supports the view that a price-sensitive customer is a brand switcher. Referring to the results of Dodson et al. (1978) who studied the concept of self-perception, it can be said that a customer is less likely to buy a brand again when buying another for the first time at a price reduction offer. Similarly, according to Lattin and Bucklin (1989), the probability of re-purchasing a brand with no price reduction incentive is very low if that brand usually offers price reduction promotions.

In this case, the customer will delay its re-purchase pending a possible price reduction offer. The use of discount coupons at time $t$ reduces the cost of brand switching for the customer and forms a habit of a switching behavior.

\subsection{Brand Switching Behavior}

Brand switchers are customers who choose a different brand from the one they last chose in order to gain a monetary or an in-kind benefit (Dodson et al., 1978). Kahn and Louie (1990) believe that customers who switch brands (switchers) behave differently when faced with price reductions from customers who are loyal to their last purchase. Switchers have a less negative attitude towards price reduction than customers who do not switch brands frequently, as they are familiar with several brands. Meanwhile, last time buyers buy a single brand and cannot formulate an attitude towards the brand sold at reduced prices. Hence, their probability of buying a brand at a low price is minimal. For non-durable products, brand switchers buy more at price reduction events than loyal customers. Therefore, we can conclude that brand switching behavior is an increasingly developing attitude in customers. 
This increase in brand switching behavior results in particular from increased competition between brands. At this level, it seems relevant to overview the theories explaining this behavior.

\subsection{Theories Explaining Brand Switching}

\subsubsection{Information Economy Theory}

The economics literature provided arguments explaining why sales decrease in rhythm after a price reduction initiative. The market is known by information asymmetry between the buyer and the seller on the offered products (Nelson, 1970). Since the customer cannot judge the quality of the brand they want to buy, they will look for a signal to trigger their purchasing decision.

Price reductions are presented as incentives to buy. A customer who is sensitive to this initiative will take this signal into account as an incentive to buy this brand. However, a high price usually presents a good quality signal. Subsequently, price reductions are poor quality signals.

Bearing on this, a customer attracted by a price reduction action will probably switch brands the next time they go shopping. Thus, information economy theory explains why a customer who is sensitive to price reductions will switch brands. It is the price reduction incentive that induces the purchase of the brand and not the product itself.

\subsubsection{Reference Price Theory}

The reference price of a brand is the threshold that is constructed during recent exposure to promotions (Lattin and Bucklin, 1989). This threshold sets up a reference base for the customer to be used in a subsequent purchase. The reference price of a brand is the last price paid by a customer. It can also be the average price of similar products.

The reference price is an essential component when buying a brand, as the customer does not judge the price of a brand separately, but rather by comparing it with other brands and with previous prices of the same brand. The reference price is important to form expectations.

It seems wise then to understand how the reference price contributes to the formation of a customer's expectations.

The customer's exposure to price reductions will develop expectations, which will be used as reference points for the subsequent choice of brands. The reference price reflects the expectations that are formed with reference the history of the promotions of that brand.

Since the reference price presents a threshold for the customer, if it is a high price, an unexpected price reduction will result in a favorable response from the customer. In a subsequent purchase, the customer's behavior will be different. There would be a remarkable decrease in the brand's sales after the price reduction, since the customer will wait for another price reduction to buy the same brand. According to Doob et al. (1969), the customer will perceive the first price paid to purchase a brand as a reference price. Consequently, any subsequent price increase will not be accepted by the customer. For this customer, as the brand becomes more expensive, it will not be purchased.

The assumption that sensitivity to price reductions can be shown to positively affect brand switching (H1) can be substantiated.

\section{The Storage Phenomenon: A Factor Explaining the Decrease in the Post-Purchase Rate}

\subsection{Sensitivity to Price Reductions and Storage}

Studies examining the effect of buying during a price reduction action on storage, or the impact of storage on customers' post-purchase behavior are scanty. Only a few authors have shown interest in this topic (Mela, Jedidi and Bowman, 1998; Chandon and Wansink, 2002).

The studies that examined the concept of storage tend to measure consumption throughout the ownership period of a brand purchased during a price reduction offer along with the post-purchase rate (Chandon and Wansink, 2002). On the other hand, research that focuses on brand switching, as a post-purchase behavior, tends to measure the decision to purchase and re-purchase the same brand.

The aim of a price reduction action is to attract more buyers to a particular brand. This promotional action is meant to encourage customers to respond immediately to such an offer. This response takes the form of a decision to purchase the promoted brand. In addition to the aim of providing an incentive to make a decision, price reductions can as well increase consumption of the same brand. This is the case for mature brands that have achieved a high level of loyalty and market share.

In the case of a price reduction action, the company believes that it stimulates consumption since sensitivity to price reductions provides an incentive to increase the quantity purchased of the promoted brand. However, if the number 
of items purchased during this action is high, the rate of subsequent purchases will slow down. This effect is measured by the time period separating a purchase during a price-reduction action and a future repurchase. This can be true as customers prefer to stock at home rather than to buy repeatedly.

Stockpiling or home storage therefore has a number of implications, in particular on the future consumption of the brand purchased in a price-reduction event and on subsequent purchasing behavior. If the customer stores for a specific period of time, both consumption and repurchasing will be affected. Storage is also a phenomenon that helps to explain the slowdown in the pace of sales during the post-purchase period. These authors highlight the importance of examining this storage response, rather than just brand switching. Indeed, if the customer is sensitive to price reductions, they will seek to take advantage of this opportunity and buy additional quantities of the same brand. This will ultimately have a negative impact on their post-purchase behavior.

This supports the hypothesis that there is a positive relationship between sensitivity to price reductions and storage $(\mathrm{H} 2)$.

\subsection{Storage and Re-purchasing}

Generally, customers do not decide on the quantity to be consumed at the time of purchase, and consumption opportunities are not planned in advance. Then, price reduction-sensitive customers tend to take advantage and buy additional quantities. Chandon and Wansink (2002) show that the quantity purchased during a price reduction event is $201 \%$ for juices and $107 \%$ for biscuits. The purchase of an additional quantity during a price reduction event will delay the re-purchase of the same brand, as customers think of buying a large quantity of the same brand.

If a customer buys one item during a price reduction action (T0) and has another item in stock, knowing that they consume two items per month, they will only re-purchase the product if there is a price reduction offer. When there is no price reduction event, the customer will only buy after a month of T0, after consuming the two items in stock. When at time T1 there was no price reduction event, the customer will only buy one item sufficient for two weeks and will buy another item at the end of these two weeks. It should be noted that the time span between a purchase and the re-purchase of a brand with a price reduction is longer (one month) than for a purchase with no price reduction (two weeks). The inter-purchase interval increases from 23\% to 36\% (depending on the type of product for non-durable products) after a price reduction action. Similarly, Chandon and Wansink (2002) show that, in the case of detergents, an increase in the quantity purchased at the time of a price reduction event (48\%) is compensated by an increase by $12 \%$ of the inter-purchase period. Customers' future price expectations depends on their prior exposure to price reduction events over a long period of time (Mela, Jedidi and Bowman, 1998). These expectations bear on the cost of holding the stock to determine the timing of the repurchase and the decision on the to-be-purchased quantity. When a customer anticipates a price increase in the future and the cost of holding the stock is not high, the quantity purchased at the time of a price reduction will be high, which will have a negative impact on the timing of the repurchase (the inter-purchase period; see Figure 1).

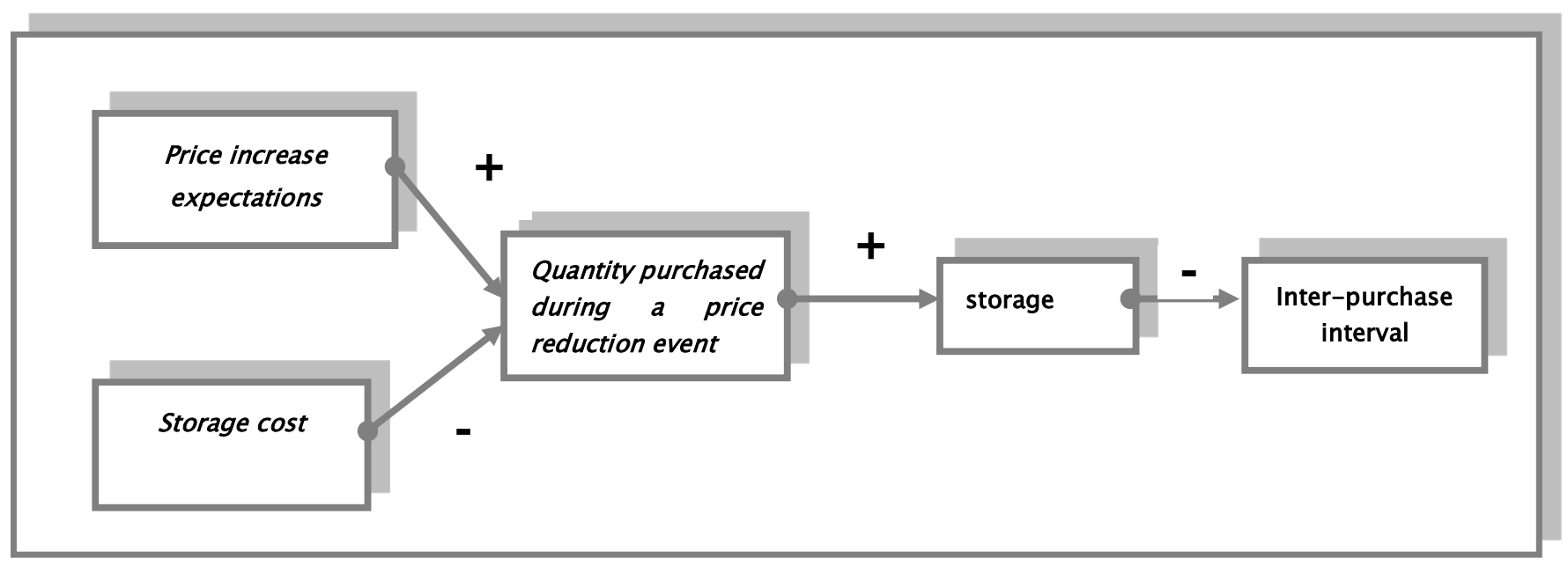

Figure 1. Model of the effect of expectations and storage cost on consumer behavior 
Mela, Jedidi and Bowman (1998) are among the first to show that the greater the quantity purchased during a price-reduction event, the more the effectiveness of that promotional action will be reduced and the longer the inter-purchase interval will be, which will manifest itself in the volatility of future demand for the same brand. Storage has a negative effect if the inter-purchase period is long. This is the case for a few types of products that are known by a long shelf life, with either a high cost of consumption or a low cost of storage.

The above proposals support the hypothesis that there is a negative relationship between storage and repurchase (H3).

Figure 2 shows the relationships between the different variables of this study, namely sensitivity to price reductions, brand switching, storage and repurchase.

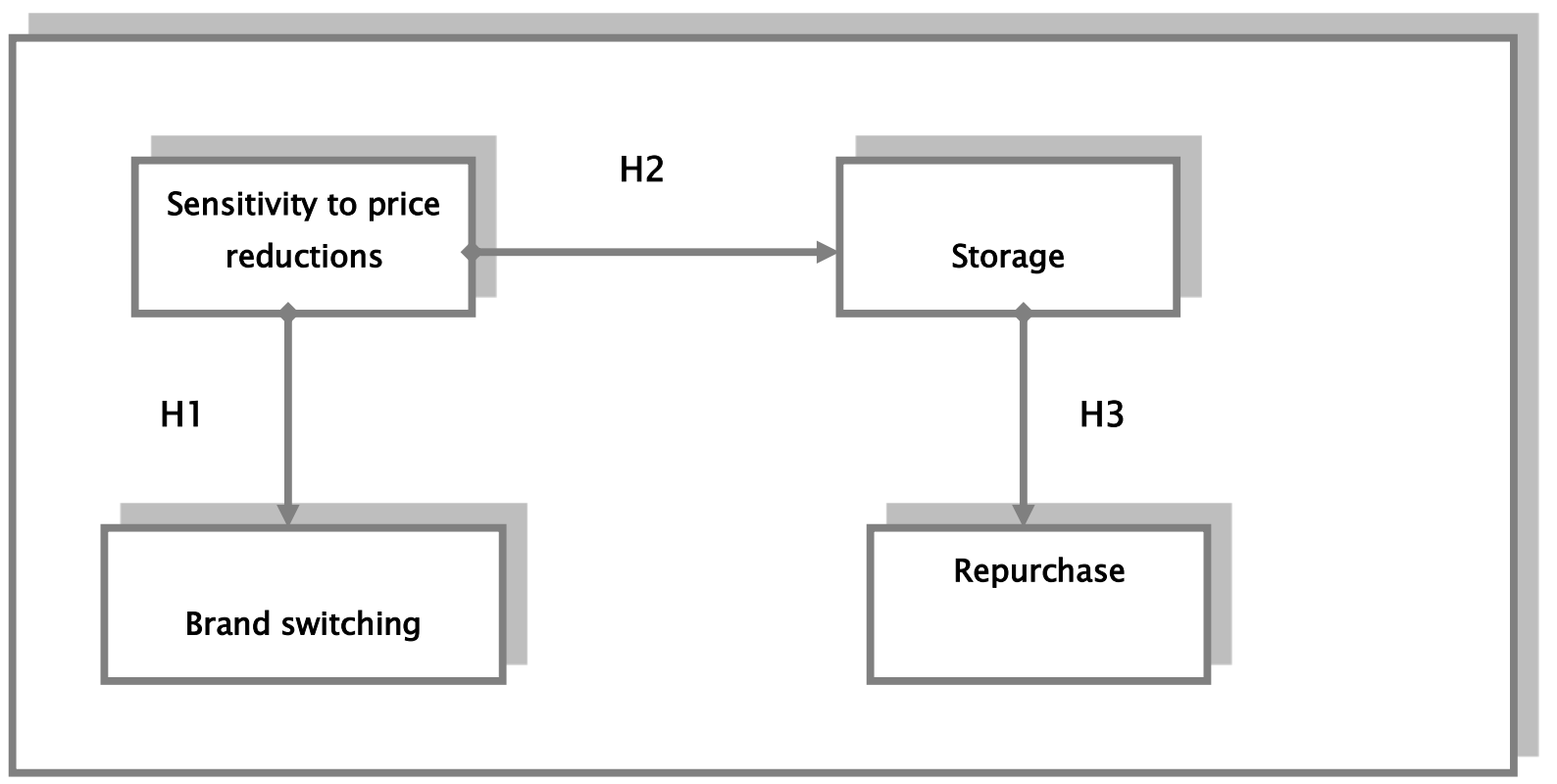

Figure 2. Model of the impact of sensitivity to price reductions on post-purchase behavior

In order to test the relationships between the different variables, a two-section questionnaire was designed. The first section probes for information on the brands usually acquired (before buying at a price reduction) and the second section targets re-purchasing behavior after buying at a price reduction.

The choice of the type of product to be studied should check two criteria. The product should therefore be subject to several price reduction events. Moreover, its purchase should be frequent in order to be able to measure brand switching behavior. Likewise, its storage condition should be checked. In order to choose a product category, a survey with the department managers of a few supermarkets revealed that cleaning products are the most sold during price reduction events. In addition, this product category figures among customers' current purchases and can be stored.

Housewives were the target of this study. In order to test our research hypotheses, a condition was set up. The respondent should purchase the product themselves in order to measure sensitivity to price reductions and repurchase. To this end, each respondent was asked orally one filter question: "Do you buy hand washing powders?".

Thus, 231 Saudi female consumers were selected as a sample representing voluntary purchasers of hand washing powder.

Thus, in order to determine whether the purchase is done during a price reduction event, seven brands of cleaning products were listed and the customer will simply tick the brand purchased during a price reduction event.

We opted for the measurement scale of sensitivity to price reduction developed by Lichtenstein, Ridgway and Netemeyer (1993) (see Table 1). 
Table 1. Measurement scale of sensitivity to price reductions

(- for me, any product with reduced price represents an opportunity to buy

2 when I buy a brand with a reduced price, I feel I did a good deal

3 I have a list of my favorite brands, yet, I buy the one with a reduced price

4 I often prefer to buy brands with reduced prices

(5 one should try to buy a brand with a reduced price

6 Compared to other people, I prefer to buy brands with reduced prices

This scale is structured around cognitive and affective dimensions and has a Cronbach's Alpha of 0.75 . The choice of this scale is justified by its recommendation by several authors, its simplicity and its relevance to the present study.

The scale developed by Raju (1980) (see Table 2) is used to measure brand switching. Its reliability was tested on two samples of 105 students and 336 housewives and was found to be 0.761 and 0.842 respectively.

Table 2. Measurement scale of brand switching

- I like to try different brands for ordinary products so as to compare them

2 I prefer to buy a brand that I often buy rather than try another I am not sure about

(3) I rarely switch the brand I like, just to try another different brand,

4 Buying the same brands is boring even if they are good

(5 I often like to buy a brand totally different from the one I usually consumer

$\boldsymbol{6}$ during the purchase, I like to discover different brands

Storage, which has been widely studied by Gupta (1988), Mela, jedidi and Bowman (1998) and Chandon and Wansink (2002), is measured over a period that varies according to the study. For example, Gupta (1988) studied this phenomenon using scanner panel data. The size of the panel is 2000 people during the 1980-1982 period. The aim of this study is to determine the contribution of storage in increasing sales during a price reduction action. We want to determine that the respondent buys an additional quantity during a price reduction event for storage purposes. To this end, we measured this variable using a single item: "During a price reduction event, I buy all the quantity I need for my future needs". In this item, our aim is to determine if the respondent buys an additional quantity during a price reduction action for storage purposes (the whole quantity), and likewise to determine its effect on the inter-purchase period (necessary for my future needs).

To measure re-purchasing, respondents were invited to respond to the following statement: "Please specify your frequency of re-purchasing the same brand". The respondent will tick on a scale ranging from 'very frequent' to 'not at all'.

\section{The Results}

\subsection{Measurement Scales Dimensionality}

To check the dimensions of our measurement scales a Principal Component Analysis was conducted. This analysis followed a three-step procedure. First of all, the items were factorized using the K-M-O (Kaiser-Meyer-Olkin) measure, Bartlett's sphericity test, a correlation analysis and the quality of communalities of the items in the final factor structure (the minimum threshold used here is 0.400 ). Then, only those dimensions whose eigenvalue is greater than or equal to 1 were retained. Finally, a factor rotation was used to improve items' loadings on the selected 
factors. This last step made it possible to name the selected dimensions by referring to item/factor correlation.

Second, the reliability of the selected factors was assessed. We examined the correlation among the items of each factor and eliminated those with low correlation coefficients. To this end, Cronbach's Alpha, a classic correlation coefficient, is chosen as a measure of reliability easily interpreted, i.e., the closer it is to 1 , the more reliable the scale is (Cronbach, 1951). A minimum of 0.7 was used as a reference coefficient to conclude that the measurement scale is reliable. Following this approach, scales with good reliability were selected. The following sections summarizes the reliability estimates of each measurement scale.

\subsubsection{Sensitivity to Price Reductions}

Applying a Principal Component Analysis and examining the reliability of the measurement scale of sensitivity to price reductions developed by Lichtenstein, Ridgway and Netemeyer (1993), we obtained the results presented in Table 3 below.

Table 3. Dimensionality of sensitivity to price reductions scale

\begin{tabular}{lcc}
\hline \multicolumn{1}{c}{ Items } & Loadings & items-factors Correlation \\
\hline $\begin{array}{l}\text { for me, any product with reduced price } \\
\text { represents an opportunity to buy }\end{array}$ & 0,405 & 0,819 \\
\hline $\begin{array}{l}\text { when I buy a brand with a reduced price, I } \\
\text { feel I did a good deal }\end{array}$ & 0,477 & 0,813 \\
\hline $\begin{array}{l}\text { I have a list of my favorite brands, yet, I buy } \\
\text { the one with a reduced price }\end{array}$ & 0,470 & 0,720 \\
\hline $\begin{array}{l}\text { I often prefer to buy brands with reduced } \\
\text { prices }\end{array}$ & 0,662 & 0,691 \\
\hline $\begin{array}{l}\text { one should try to buy a brand with a reduced } \\
\text { price }\end{array}$ & 0,519 & 0,685 \\
\hline $\begin{array}{l}\text { Compared to other people, I prefer to buy brands } \\
\text { with reduced prices }\end{array}$ & 0,671 & 0,637 \\
\hline K-M-O & & 0,850 \\
\hline Variance explained (cumulative) & $03,387 \%$ \\
\hline Cronbach's Alpha & 0.819 \\
\hline
\end{tabular}

The measurement scale of sensitivity to price reductions has a one-dimensional structure. Internal consistency among the items is satisfactory with a K-M-O of 0.850 . Correlation between all items and this factor exceeds $60 \%$. A single dimension is thus retained which recovers more than half of the variance. Internal correlation between all items is good and estimated at 0.82 .

\subsubsection{Brand Switching}

The results about the dimensionality of the brand switching measurement scale developed by Raju (1980) are summarized in Table 4 below.

Table 4. Dimensionality of the brand switching scale

\begin{tabular}{lccc}
\hline \multicolumn{1}{c}{ Items } & Loadings & \multicolumn{2}{c}{ items-factors correlation } \\
\cline { 3 - 3 } & & F1 & F2 \\
\hline $\begin{array}{l}\text { I like to try different brands for ordinary products } \\
\text { so as to compare them }\end{array}$ & 0,449 & 0,665 \\
\hline $\begin{array}{l}\text { I prefer to buy a brand that I often buy rather } \\
\text { than try another I am not sure about }\end{array}$ & 0,637 & \\
\hline $\begin{array}{l}\text { I rarely switch the brand I like, just to try another } \\
\text { different brand, }\end{array}$ & 0,746 & 0,779 \\
\hline
\end{tabular}




\begin{tabular}{lcc}
\hline $\begin{array}{l}\text { Buying the same brands is boring even if they are } \\
\text { good }\end{array}$ & 0,462 & 0,680 \\
\hline $\begin{array}{l}\text { I often like to buy a brand totally different from } \\
\text { the one I usually consumer }\end{array}$ & 0,658 & 0,794 \\
\hline $\begin{array}{l}\text { during the purchase, I like to discover different } \\
\text { brands }\end{array}$ & 0,426 & 0,610 \\
\hline K-M-O & & 0,601 \\
\hline Variance explained (cumulative) & \multicolumn{2}{|c}{$60,301 \%$} \\
\hline Cronbach's Alpha & $\mathbf{F 1}$ & 0,761 \\
\hline
\end{tabular}

The final structure of the brand switching measurement scale is two-dimensional. The items show average internal consistency $(\mathrm{K}-\mathrm{M}-\mathrm{O}=0.601)$ and acceptable representation in the final factor structure. Bearing on the item-factor correlations, the first dimension represents "variety seeking" and the second "brand attachment". The variance explained by these two factors is $66.301 \%$.

For the first dimension, alpha coefficient is relatively satisfactory $(0.761)$. The second dimension shows an internal correlation estimated at 0.740 despite the limited number of items (two items).

\subsection{Hypothesis Testing}

This section presents the results about our hypothesis. Table 5 reports a summary of the different relationships between our variables.

Table 5. Presentation of the model's equations

\begin{tabular}{ll}
\hline \multicolumn{1}{c}{ Equations } & \multicolumn{1}{c}{ Labels } \\
\hline $\mathbf{C H M}=\mathbf{a}+\alpha_{1} \mathbf{S R P}+\zeta_{1}$ & SRP: sensitivity to price reductions \\
$\mathrm{SKG}=\mathbf{b}+\alpha_{2} \mathbf{S R P}+\zeta_{2}$ & CHM: brand switching \\
$\mathbf{R C H}=\mathbf{c}+\alpha_{3} \mathbf{S K G}+\zeta_{3}$ & SKG: storage \\
\end{tabular}

The linear regression method was used. This method is scientifically appropriate to explain the relationships between continuous variables. Applying the linear regression method yielded the results summarized in Table 6 below.

Table 6. Linear regression results

\begin{tabular}{|c|c|c|c|c|c|}
\hline Coefficients & Value & $\mathbf{t}$ & Significance & Equations & Hypothesis \\
\hline$\alpha_{1}$ & 0,280 & 4,229 & $\mathrm{p}<0,05$ & $\mathrm{CHM}=0.280 \mathrm{SRP}+\zeta_{1}$ & Retained \\
\hline$\alpha_{2}$ & 0,457 & 7,441 & $\mathrm{p}<0,05$ & $\begin{array}{l}\text { SKG }=2.736+0.457 \\
+\zeta_{2}\end{array}$ & Retained \\
\hline$\alpha_{3}$ & $-0,247$ & $-3,691$ & $\mathrm{p}<0,05$ & $\underset{\zeta_{3}}{\mathrm{RCH}}=2.737-0.247 \mathrm{SKG}+$ & Retained \\
\hline
\end{tabular}

As the coefficients $\alpha 1, \alpha 2$ and $\alpha 3$ are significant, the hypotheses $\mathrm{H} 1, \mathrm{H} 2$ and $\mathrm{H} 3$ cannot be rejected. This points to a 
statistically significant relationship between sensitivity to price reductions, brand switching and storage and between re-purchasing and storage.

\section{Discussion and Conclusion}

A review of the literature has highlighted the effect of sensitivity to price reductions on post-purchase behavior. This assumption was supported by the results of our study of cleaning products on a sample of 231 Saudi female consumers.

The positive impact of sensitivity to price reduction on brand switching implies that price-sensitive customers tend to switch brands not only because they gain in satisfaction but also because the brand has a price reduction. This type of customer will have to "follow" no longer "a brand" but rather "a price". They are likely to try any brand with a price reduction without having an emotional attachment to any of them.

Price-sensitive customers often try to take advantage of occasional price reductions to stock a maximum quantity of the same brand to meet their needs in future periods. They consider price reductions as opportunities they should not miss and occasions in which they should buy to save additional costs tomorrow.

After having stocked their needs, customers tend not to re-purchase at the same rate as they were before exposure to a price reduction. The pace of their purchases will slow down until the stock acquired at the time of the price reduction runs out. Then, they may either resume the same pace of purchases or even switch to other brands offering lower prices rather than stick to the brand purchased previously. This leads to the conclusion that, although a price-reduction event may in some circumstances improve the short-term profitability of firms, it may have negative effects on their customers' post-purchase behavior. The company will experience a slowdown in the pace of its sales following the price reduction opportunity. This may affect the revenues generated by the latter action. Therefore, buying during price reduction events increases customers' willingness to take advantage of any price reduction and to switch brands.

The negative effect of sensitivity to price reductions on post-purchase behavior should draw the attention of marketers to the importance of scheduling events well-planned price reduction actions. They should ensure a good price communication strategy that prevents any negative perception of the price reduction event and guarantees re-purchase behavior. This involves scheduling price reduction events and their appropriate times over the current year. The aim is to attract and retain customers who are sensitive to price reductions.

The efforts made to maintain this category of customers should not be at the expense of loyal customers since these latter may develop a feeling of unfairness and dissatisfaction. Good and fair price management is very well needed to ensure the success of price reduction events.

However, our study is not without limitations. Other variables could have been identified to better determine the effect of sensitivity to price reductions on post-purchase behavior, such as dissatisfaction. At the methodological level, the results obtained on cleaning products may not be the same for other product categories. Moreover, the cross-sectional nature of our study does not allow us to track subsequent behavior and study how customer attitudes may vary in time.

Despite these limitations, our study opens the way for further research. A study on the management of the feeling of fairness between the different categories of the company's customers would be interesting. Studying the effect of customer sensitivity to price reduction on loyal customers and its manifestation would be of a paramount importance in guiding companies' pricing strategies. Conducting longitudinal study to monitor the behavior and attitudes of customers from the time they are exposed to a price-reduction event until after they have made a repurchase may offer a great deal of insights.

\section{References}

Chandon, P., \& Wansink, B. (2002). When are stockpiled products consumer faster? A convenience salience framwork of post purchase consumption incidence and quantity. Journal of Marketing Research, 39(3), 321-335

Chandon, P. (1994). Dix ans de recherches sur la psychologie et le comportement des clients face à la promotions. Recherche et Application en Marketing, IX(3/94).

Colombier, M., \& Hourcade, J. C. (1989). Développement des réseaux et modulations spatio-temporelles des tarifs : l'équité territoriale revisitée. Revue économique, 40(4), 649-677.

Dodson, J. A., Tybout, A. M., \& Sternthal, B. (1978). Impact of deals and deal retraction on brand switching. Journal of Marketing Research, XV. 
Froloff, L. (1992). La sensibilité du client à la promotion des ventes : de la naissance à la maturité. Recherche et Application Marketing, VII.

Gao, H., Zhang, Y., \& Mittal, V. (2017). How does local-global identity affect price sensitivity?. Journal of Marketing, 81(3), 62-79.

Gupta, S. (1988). Impact of sales promotions on when, what, and how much to buy. Journal of Marketing Research.

Kahn, B. E., \& Louie, T. A. (190). Effects of retraction of price promotions on brand choice behavior for variety-seeking and last-perchase-loyal consumers. Journal of Marketing Research.

Lattin, J. M., \& Bucklin, R. E. (1989). Reference effects of price and promotion on brand choice behaviour. Journal of Marketing Research, XXVI.

Lichtenstein, D. R, Ridgway, N. M., \& Netemeyer, R. G. (1993). Price perceptions and consumer shopping behavior : A field study. Journal of Marketing Research, 30.

Mela, C., Jedidi, K., \& Bowman, D. (1998). The long term impact of promotion on consumer stockpiling behaviour. Journal of Marketing Research.

Rezgar, M., \& Olga, M. (2019). Strategic Price Response in the Differentiated U.S. Yogurt Market. International Journal of Economics and Financial Issues.

Steven, D., John, D., \& Svetlana, B. (2020). The effects of competitive context on consumer response to price changes. Journal of Marketing Management.

Sudipt, R., \& Tat, C. (2014). Amar C: Price Expectations and Purchase Decisions: Evidence from an Online Store Experiment. Customer Needs and Solutions.

Zollinger, M., \& Desmet, P. (1997). Le prix: De l'analyse conceptuelle aux méthodes de fixation. Edition Economica, Paris.

\section{Copyrights}

Copyright for this article is retained by the author(s), with first publication rights granted to the journal.

This is an open-access article distributed under the terms and conditions of the Creative Commons Attribution license (http://creativecommons.org/licenses/by/4.0/). 